\title{
CLINICAL PRACTICE Clinical Images Caval Perforation from a Malpositioned Inferior Vena Cava Filter
}

\author{
Jürgen L. Holleck, M.D. ${ }^{1,2}$, Eric Y. Chen, B.S. ${ }^{3}$, and Jason Bonomo, M.D. ${ }^{1}$ \\ 'Department of Internal Medicine, Yale University School of Medicine, New Haven, CT, USA; ${ }^{2}$ Department of Medicine,, Veterans Affairs \\ Connecticut Healthcare System West Haven Campus, West Haven, CT, USA; ${ }^{3}$ Yale University School of Medicine, New Haven, CT, USA.
}

KEY WORDS: IVC filter; inferior vena cava filter; complications.

J Gen Intern Med 34(7):1358-9

DOI: $10.1007 / \mathrm{s} 11606-019-04933-8$

(C) Society of General Internal Medicine (This is a U.S. government work and not under copyright protection in the U.S.; foreign copyright protection may apply) 2019

\begin{abstract}
A 71-year-old man with a history of deep venous thrombosis, pulmonary embolism, patent foramen ovale, cerebrovascular accident with hemorrhagic conversion, and inferior vena cava (IVC) filter placement at an outside hospital 2 years earlier underwent a CT scan which demonstrated a malpositioned IVC filter projecting outside of the lumen (Fig. 1). Current medications included rivaroxaban. Interventional radiology and vascular surgery were consulted regarding possible removal, but removal was deemed to be too high risk in the absence of symptoms. Late complications from IVC filters including caval, aortic, and duodenal perforation
\end{abstract}

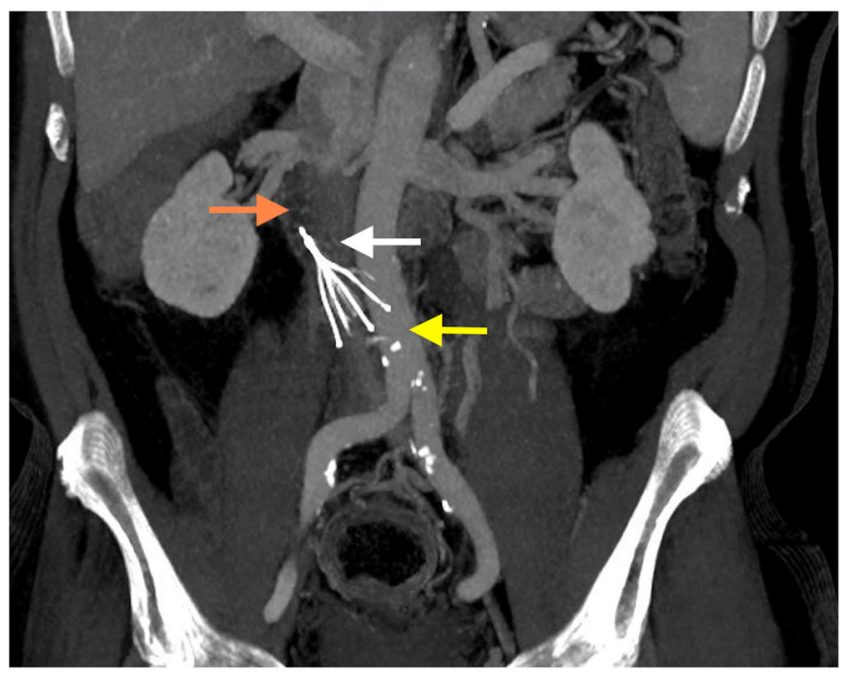

Figure 1 Maximal intensity projection image from an abdominal CT scan showing a malpositioned IVC filter with the hook protruding outside the inferior vena cava (white arrow) and abutting the duodenum (orange arrow) and the struts perforating the IVC and abutting the aorta (yellow arrow).

Received July 26, 2018

Revised November 20, 2018

Accepted February 21, 2019

Published online April 10, 2019 have been reported. ${ }^{1}$ Other complications include IVC thrombosis, ${ }^{2}$ filter fracture with embolization, ${ }^{3}$ and filter migration. ${ }^{4}$ The FDA recommends that IVC filters be removed as soon as protection from pulmonary embolism is no longer needed, and issued a quantitative decision analysis favoring removal between 25 and 54 days after implantation. ${ }^{5-7}$ However, removal is frequently not done. An open-label multicenter trial (PRESERVE trial-NCT02381509) is currently underway to further address the safety and efficacy of IVC filters. In the meantime, indications for IVC filters are limited to acute proximal deep venous thrombosis or pulmonary embolism with contraindication to anticoagulation. ${ }^{8}$ Guidelines recommend against IVC filter placement in patients with venous thromboembolism who are treated with anticoagulation. ${ }^{9}$

Corresponding Author: Jürgen L. Holleck, M.D.; Department of Medicine, Veterans Affairs Connecticut Healthcare System West Haven Campus, West Haven, CT, USA (e-mail: Jurgen.Holleck@va. gov).

\section{Compliance with Ethical Standards:}

Conflict of Interest: The authors declare that they do not have a conflict of interest.

\section{REFERENCES}

1. Veroux M, Tallarita T, Pennisi M, Veroux $\mathbf{P}$. Late complication from a retrievable inferior vena cava filter with associated caval, aortic, and duodenal perforation: a case report. J Vasc Surg. 2008;48(1):223-225.

2. McAree BJ, O'Donnell ME, Fitzmaurice GJ, Reid JA, Spence RA, Lee B. Inferior vena cava thrombosis: a review of current practice. Vasc Med. 2013;18(1):32-43.

3. Nicholson $\mathbf{W}$, Nicholson $\mathbf{W J}$, Tolerico $\mathbf{P}$, et al. Prevalence of fracture and fragment embolization of Bard retrievable vena cava filters and clinical implications including cardiac perforation and tamponade. Arch Intern Med. 2010;170(20): 1827-1831.

4. Bochenek KM, Aruny JE, Tal MG. Right atrial migration and percutaneous retrieval of a Gunther Tulip inferior vena cava filter. J Vasc Interv Radiol. 2003; 14(9 Pt 1):1207-1209.

5. Arous EJ, Messina LM. Temporary inferior vena cava filters: how do we move forward?, Chest. 2016;149(5):1143-1145.

6. Morales JP, Li X, Irony TZ, Ibrahim NG, Moynahan M, Cavanaugh KJ Jr. Decision analysis of retrievable inferior vena cava filters in patients without pulmonary embolism. J Vasc Surg Venous Lymphat Disord. 2013;1(4):376-384. 
7. http://wayback.archive-it.org/7993/20170722215731/https://www.fda gov/MedicalDevices/Safety/AlertsandNotices/ucm396377.htm. Accessed $12 / 20 / 2018$.

8. Guyatt GH, Akl EA, Crowther M, et al. Executive summary: Antithrombotic Therapy and Prevention of Thrombosis, 9th ed: American College of
Chest Physicians Evidence-Based Clinical Practice Guidelines. Chest. 2012;141(2 Suppl):7S-47S.

9. Kearon C, Akl EA, Ornelas J, et al. Antithrombotic therapy for VTE disease: CHEST Guideline and Expert Panel Report. Chest. 2016;149(2):315-352.

Publisher's Note Springer Nature remains neutral with regard to jurisdictional claims in published maps and institutional affiliations. 